\title{
Trade, Standards, and the Political Economy of Genetically Modified Food
}

\author{
Kym Anderson (World Bank, CEPR and University of Adelaide), \\ Richard Damania (University of Adelaide) and
}

Lee Ann Jackson (WTO Secretariat, Geneva)

\author{
Contact author: \\ Kym Anderson \\ Development Research Group \\ World Bank \\ 1818 H Street NW \\ Washington DC 20433 USA \\ Phone +1 2024733387 \\ Fax +12025221159 \\ kanderson@worldbank.org
}

World Bank Policy Research Working Paper 3395, September 2004

The Policy Research Working Paper Series disseminates the findings of work in progress to encourage the exchange of ideas about development issues. An objective of the series is to get the findings out quickly, even if the presentations are less than fully polished. The papers carry the names of the authors and should be cited accordingly. The findings, interpretations, and conclusions expressed in this paper are entirely those of the authors. They do not necessarily represent the view of the World Bank, its Executive Directors, or the countries they represent. Policy Research Working Papers are available online at http://econ.worldbank.org.

Kym Anderson is Professor of Economics at, but on leave from, the University of Adelaide, and is now Lead Economist (Trade Policy) in the Development Research Group of the World Bank in Washington DC. Richard Damania is Associate Professor of Economics at the University of Adelaide. Lee Ann Jackson is with Agriculture Division of the WTO Secretariat in Geneva. This paper was first drafted while all three authors were with the Centre for International Economic Studies at the University of Adelaide. We acknowledge with thanks funding support from Australia's Rural Industries Research and Development Corporation and the Australian Research Council. 


\title{
Trade, Standards, and the Political Economy of Genetically Modified Food
}

\author{
Kym Anderson, Richard Damania and Lee Ann Jackson
}

\begin{abstract}
A common-agency lobbying model is developed to help understand why North America and the European Union have adopted such different policies toward genetically modified (GM) food. Our results show that when firms (in this case farmers) lobby policy makers to influence standards and consumers and environmentalists care about the choice of standard, it is possible that increased competition from abroad can lead to strategic incentives to raise standards, not just lower them as shown in earlier models. We show that differences in comparative advantage in the adoption of GM crops may be sufficient to explain the trans-Atlantic difference in GM policies. On the one hand, farmers in a country with a comparative advantage in GM technology can gain a strategic cost advantage by lobbying for lax controls on GM production and usage at home and abroad. On the other hand, when faced with greater competition, the optimal response of farmers in countries with a comparative disadvantage in GM adoption may be to lobby for more-stringent GM standards. Thus it is rational for producers in the EU (whose relatively small farms would enjoy less gains from the new biotechnology than broad-acre American farms) to reject GM technologies if that enables them and/or consumer and environmental lobbyists to argue for restraints on imports from GM-adopting countries. This theoretical proposition is supported by numerical results from a global general equilibrium model of GM adoption in America without and with an EU moratorium.
\end{abstract}

Key words: GMOs, political economy, regulation of standards, trade policy

JEL codes: F13, O33, O38, Q17, Q18 


\section{Trade, Standards, and the Political Economy of Genetically Modified Food}

\section{Introduction}

As of 2002, genetically modified (GM) varieties of maize, soybeans and canola accounted for one-quarter of the area planted to those crops globally, having been close to zero prior to 1996 . However, virtually all of those GM food crops are grown in just three countries: Argentina, Canada and the United States where, because of production cost savings and few regulatory impediments, the GM shares of those crops average more than 60 percent (James 2003). In the European Union, by contrast, a moratorium introduced in 1998 has ensured virtually no GM crop varieties have been approved for production or sale in its member countries, ostensibly in response to strong opposition by some consumer and other community groups concerned about their potentially adverse impacts on food safety and the environment. That moratorium had an immediate and dramatic impact on trade in these three products: in the mid-1990s, the three GM-adopting countries had shares of the EU market that were similar to their shares in world trade for those three crops, but by the end of the 1990s they had lost market share to GM-free suppliers, particularly Brazil for maize and soybeans and Australia and Central Europe in the case of canola (Table $1)$.

Why have European and other countries not yet followed the American adoption of GM food? The conventional wisdom is that Europeans care more about the natural environment and have less trust in their food safety regulators than do Americans (see, e.g., Bernauer 2003). Given the hard-line EU stance, other foodexporting countries have so far avoided this new biotechnology for fear that if any 
GM crops are grown in or even imported into those food-exporting countries they too will be denied access to EU markets. The most important example is China (representing almost one-fifth of the world's food economy), which has been unwilling to approve GM food production ostensibly because it was denied access to the EU market in 1999 for soy sauce that may have been produced using GM soybeans from the US. This fear of losing EU market access was also the ostensible reason Zambia, Zimbabwe and other poor African countries did not want to accept US humanitarian food aid in the form of GM maize in 2002-03. That added to the frustration of exporters of GM crops, so much so that in August 2003 the US, Canada and Argentina initiated dispute settlement proceedings at the World Trade Organization against GM regulations in EU member states. It has also led biotechnology corporations to alter their R\&D efforts away from food and more toward pharmaceuticals (which have faced almost no opposition by consumers).

Clearly this is an important issue affecting not only world food trade and aid but also, through dampening the investment incentives of agricultural biotech firms, the prospect of relieving hunger in developing countries via another green revolution (following the one generated by the dwarf wheat and rice varieties released in Asia and elsewhere in the 1960s). ${ }^{1}$

An important first step in resolving this trade dispute is to understand the motives of EU policymakers. Certainly consumer and environmental groups have influenced policy there, but they have been active in America also. This suggests the need to consider producer and national economic interests as well, bearing in mind the different production conditions in America and Europe. Two recent insightful papers have addressed this issue by looking at the welfare effects of GM adoption for producers and consumers using partial equilibrium economic models (Fulton and 
Giannakas 2004; Lapan and Moschini 2004). The present paper adopts instead a political economy model to take explicit account of the political influence of specialinterest groups, most notably in this case farmers.

Given that GM products offer potential savings and management flexibility to farmers, it is often assumed that without government constraints farmers would adopt GM varieties. However, recent research on farmer adoption of these products stresses the complex nature of GM adoption decisions and suggests that those farming relatively small areas of land prefer to delay or avoid adoption (Fernandez-Cornejo and McBride, 2002; Marra, Pardey and Alston 2002). Such farmers, who would gain relatively little from adopting GM varieties and yet would face increased competition from successful adopters, have an incentive to join with anti-GM groups in influencing public policy in ways that limit their exposure to greater competition.

In developing a model to analyze the political economy of GM food standards in trading economies that captures the distinguishing characteristics of the GM policy debate, this paper invokes the common-agency lobbying model of Grossman and Helpman $(1994,1995)$. An important implication of the common-agency literature is that outcomes are truthful, implying that agents choose the intensity of lobbying (for example through political contributions) based on their expected gain from a policy. Thus farmers are assumed to lobby for more-permissive or more-stringent regulations depending on how they reflects farmers' commercial interests. ${ }^{2}$

Our results suggest that heightened domestic consumer or environmentalist opposition to GM crops is not the only reason why there has been a moratorium on the production and sale of GM foods in regions like the EU. Rather, differences in comparative advantage in the adoption of GM crops may be sufficient to explain the trans-Atlantic difference in GM policies. On the one hand, it is rational for producers 
in the EU (whose relatively small farms would enjoy less gains from the new biotechnology than broad-acre American farms) to reject GM technologies if that enables them, with the help of consumer and environmental lobbyists, to argue for restraints on imports from GM-adopting countries. On the other hand, farmers in a country with a comparative advantage in GM technology can gain a strategic cost advantage by lobbying for lax controls on GM production and usage at home and abroad. When faced with a more efficient competitor, the optimal response of farmers in countries with a comparative disadvantage in GM adoption is to lobby for (or at least not resist) more-stringent GM standards. In this way strategic and political factors combine to amplify country-specific differences, leading to a greater divergence of policies than would occur in the absence of producer lobbying.

The links between environmental and safety regulations and special interest group lobbying have been highlighted in a large and growing literature. For example, those examining the strategic use of agricultural product quality standards as trade barriers typically focus on the incentives countries face to lower their product standards in order to gain access to foreign markets (Bockstael 1984; Bredahl et al. 1987; Barrett 1994). Fischer and Serra (2000) extend these analyses to examine the strategic use of minimum standards for consumption externalities. In a result that differs from the literature that stresses the potential for the "race to the bottom" to lead to the adoption of less-restrictive standards, Fischer and Serra show that when firms compete in the home country, the social planner may raise standards in order to maximize social welfare. Our results show that when firms lobby policy makers to influence standards and consumers and environmentalists care about the choice of standard, it is also possible that increased competition can lead to strategic incentives 
to raise standards. To our knowledge, this has not been previously identified in the literature.

Our model extends the classic models of trade and product differentiation in several ways. In general the literature examining the adoption of quality standards uses a monopolistic competition model of vertical product differentiation and assumes that consumers benefit from improved quality (see, for example, Flam and Helpman 1987; Boom 1995). We instead adopt a strategic trade framework and allow consumer preferences for standards to vary. This provides additional insights into the political economy of standards decisions by allowing us to investigate the combined effects in an open economy on the lobbying incentives of producers of differences in both producer benefits from and consumer aversion to GM technologies. We also allow for the two possibilities that the new GM technology could either improve or worsen the environment.

The paper proceeds as follows. Section 2 describes a model that emphasizes the ability of producers to influence government policy decisions through monetary contributions. Section 3 highlights important analytical results provided by the model. Section 4 summarizes some new computable general equilibrium results that lend empirical support to the model's findings. The paper then concludes with a discussion of the more nuanced analysis of the political economy underlying GM regulations, and points to ways of extending the analysis.

\section{The Political Economy Model}

Consider a two-country world in which (say) a low-cost genetically modified maize variety has been developed. Country $i$ is a net maize exporter while country $j$ is 
a net maize importer (bearing in mind that maize self-sufficiency is 95 percent in the EU and 125 percent in the US). Let superscripts denote the origin of production and subscripts the destination. Maize export sales from country $i$ to country $j$ are denoted $X_{j}^{i}$, while $X_{j}^{j}$ denotes the domestic sales of country $j$ 's maize within its own market and analogously $X_{i}^{i}$ denotes the domestic sales of country $i$ 's maize in its own market. Output in each country is produced by means of an input vector $\left(z_{i}, g_{i}\right)(i, j=$ 1,$2 ; i \neq j$ ) where $g_{i}$ represents the quantity of GM inputs (such as say maize seed sown) and $z_{i}$ denotes all other inputs including non-GM maize seeds.

On the demand side, consumers have concerns about food containing GMOs. In market $i$, the domestic maize price is given by $P_{i}^{i}\left(X_{i}^{i}, \gamma^{i} g^{i}\right)$ where $\gamma^{j}$ is a parameter representing domestic consumers' aversion to food containing GMOs. It is assumed that the price declines with ( $i$ ) the quantity supplied, (ii) the level of GM inputs used, and the level of consumer aversion to GM inputs. That is, $\partial P_{i}^{i} / \partial X_{i}^{i}<0, \partial P_{i}^{i} / \partial\left(g^{i} \gamma^{i}\right)<0$

Similarly, the price received by country $i$ farmers for sales in export market $j$ is $P_{j}^{i}\left(X_{j}^{i}, X_{j}^{j}, \gamma^{j} g^{i}, \gamma^{j} g^{j}\right)$ where $\gamma^{j}$ represents consumers' aversion to GMOs in country $j$. It is assumed that prices decline with supplies in country $j$, so $\partial P_{j}^{i} / \partial X_{j}^{i}<0, \partial P_{j}^{i} / \partial X_{j}^{j}<0$, and that increased GM inputs by producers in country $i$ lowers the price that they receive in the export market $j$, so $\partial P_{j}^{i} / \partial\left(\gamma^{j} g^{i}\right)<0$. Furthermore, increased GM inputs by producers in country $j$ lowers relative demand for $j$ 's maize. Because the two countries' maizes are substitutes in consumption, this in turn leads to a higher demand (and price) for country $i$ 's maize, so $\partial P_{j}^{i} / \partial\left(\gamma^{j} g^{j}\right)>0$. 
Analogously, the price received by country $j$ on its (domestic) sales is $P_{j}^{j}\left(X_{j}^{j}, X_{j}^{i}, \gamma^{j} g^{i}, \gamma^{j} g^{j}\right)$. The same functional relations apply in country $\mathrm{j}$ : $\partial P_{j}^{j} / \partial X_{j}^{j}<0, \partial P_{j}^{j} / \partial X_{j}^{i}<0, \partial P_{j}^{j} / \partial \gamma^{j} g^{j}<0, \partial P_{j}^{j} / \partial \gamma^{j} g^{i}>0$.

Let total production in country $i$ be $X^{i}=X_{i}^{i}+X_{j}^{i}$ and be represented by the quasi-concave production function $X^{i}=F^{i}\left(z^{i}, g^{i}\right),(i=1,2 ; i \neq j)$ where $\partial \hat{X}^{i} / \partial z^{i}>0, \partial \hat{X}^{i} / \partial g^{i}>0, \partial^{2} \hat{X}^{i} / \partial z^{i 2}<0, \partial^{2} \hat{X}^{i} / \partial g^{2}{ }_{i}<0, \partial^{2} \hat{X}^{i} /\left(\partial z^{i} \partial g^{i}\right)>0$. The dual to this production function is the cost function $c^{i}\left(X^{i}, w^{i}, r^{i}\right)$ where $w^{i}$ is the price of input $z^{\mathrm{i}}$ and $r^{i}$ is the price of input $g^{i}$.

The government is assumed to regulate the use of GM inputs in domestic production by choosing $g^{i}$, the allowable level of the GM input. In situations where this regulation binds, the cost function is denoted $C^{i}\left(X^{i}, \bar{g}^{i}\right)$ where $\bar{g}^{i}$ is the regulated level of the GM input. ${ }^{3}$

The profitability for a country's farmers of adopting GM technology depends on a variety of factors such as the scale of production, factor intensities, climatic conditions and farmer education and experience (Fernandez-Cornejo and McBride 2002). Farm size in particular has been cited as an important determinant of farmer willingness to adopt GM technology in the early stages of its diffusion (van Meijl and van Tongeren 2002; Fernandez-Cornejo and McBride 2000). ${ }^{4}$ That is, country $i$ with a relatively large endowment of land per farmer enjoys a comparative advantage in the use of GM technology relative to country $j$. This is captured by modifying the cost functions to $\theta^{i} C^{i}\left(X^{i}, \bar{g}^{i}\right), \theta^{j} C^{j}\left(X^{j}, \bar{g}^{j}\right)$ where $\theta^{i}<\theta^{j}$.

Following Grossman and Helpman (1994), the government in each country is assumed to be self-interested and cares about political contributions. Knowing this, farmers in each country have an incentive to offer their government political 
contributions $\left(S^{i}\right)$ in return for favorable policies. The payoff to each of the $n^{i}$ producers in country $i$ is defined by

$\Pi^{i}=P_{i}^{i}\left(X_{i}^{i}, \gamma^{i} g^{i}\right) X_{i}^{i}+P_{j}^{i}\left(X_{j}^{i}, X_{j}^{j}, \gamma^{j} g^{i}, \gamma^{j} g^{j}\right) X_{j}^{i}-\theta^{i} C^{i}\left(X^{i}, \bar{g}^{i}\right)-S^{i}$

where $S^{i}$ denotes political contributions. Analogously the payoffs to each of the $n^{j}$ producers in country $j$ is

$\Pi^{j}=P_{j}^{j}\left(X_{j}^{j}, X_{j}^{i}, \gamma^{j} g^{j}, \gamma^{j} g^{i}\right) X_{j}^{j}-\theta^{j} C^{j}\left(X_{j}^{j}, \bar{g}^{j}\right)-S^{j}$

\section{The sequence of GMO policy choices and responses}

Since the model contains two countries and three agents in each country (government, producers, consumers), it is necessary to specify the chronology of moves between countries and within each country. Consistent with recent events, where the U.S. has led the world in setting GM regulations, country $i$ is assumed to be the leader and optimally sets its GM regulations first. Observing these policies, regulations in country $j$ are then optimally determined.

In country $i$ the sequence of events is as follows once the GM technology becomes available. First, producers offer political contributions to their government in order to influence GM policies. In the second stage, the government determines its policy $\left(\bar{g}^{i}\right)$ to maximize its own payoff. Finally, producers determine the level of GM crop output. Once the GM policy and production level have been set in the leader country $i$, the follower country $j$ determines its GM policy and production level in an identical sequential manner. By backward induction we begin by solving the final stage of the game in country $j$. 
Output Choice in Country j (Stage 3 in country j)

Maximizing (1b) with respect to $X_{j}^{j}$ yields the first-order condition

$$
\frac{\partial \Pi^{j}}{\partial X_{j}^{j}}=\left(\frac{\partial P_{j}^{j}}{\partial X_{j}^{j}} X_{j}^{j}+P_{j}^{j}-\theta^{j} \frac{\partial C^{j}}{\partial X_{j}^{j}}\right)=0 .
$$

To determine how output varies with GM regulations, totally differentiate equation (2) to obtain

$$
\frac{d X_{j}^{j}}{d \bar{g}^{i}}=\frac{-\partial P_{j}^{j} / \partial \bar{g}^{i}}{\partial^{2} \Pi^{j} / \partial X_{j}^{j 2}}>0 .
$$

Observe that (3a) is always negative since by assumption $\partial P_{j}^{j} / \partial \bar{g}^{i}>0$ and by the second-order conditions $\partial^{2} \Pi^{j} / \partial X_{j}^{j 2}<0$. Thus, an increase in the GM content of imports shifts demand to the domestic product and leads to an expansion in domestic production in country $j$.

Turning next to the effects of an increase in the GM content of domestic produce in country $j$, note that

$$
\frac{d X_{j}^{j}}{d \bar{g}^{j}}=\frac{-\left(\partial P_{j}^{j} / \partial \bar{g}^{j}-\theta^{j}\left(\partial^{2} C^{j} / \partial X_{j}^{j} \partial \bar{g}^{j}\right)\right)}{\partial^{2} \Pi^{j} / \partial X_{j}^{j 2}} \leq(>) 0 .
$$

An increase in the GM content of domestic produce has an ambiguous effect on domestic production levels, because of conflicting signs in the numerator. Intuitively, a higher GM level lowers production costs and thus leads to an expansion in output, ceteris paribus. This is captured in the term $\theta^{j}\left(\partial^{2} C^{j} / \partial X_{j}^{j} \partial \bar{g}^{j}\right)>0$. On the other hand, consumer aversion to higher GM content leads to a decline in demand. When this demand effect outweighs (is outweighed by) the cost effect, higher GM use will lead to a contraction (expansion) in domestic output. 
Government Policy Response in Country j (Stage 2 in country j)

Following Grossman and Helpman (1994), we assume the government is self interested and maximizes a weighted sum of political contributions and social welfare. Its utility $\Omega$ is thus

$\Omega^{j}=\alpha^{j} W^{j}+n^{j} S^{j}$

where $\alpha^{j}$ is the weight given to social welfare $W^{j}$ and $n^{j} S^{j}$ are political contributions in country $j$. Social welfare is given by the sum of producers' and consumers' surpluses, less any perceived environmental change from the use of input $g$, denoted $D\left(\bar{g}^{j}\right)$. We allow for two alternative scenarios. First, it is possible that increased GM usage may result in environmental damage (perhaps through genetic pollution), so that $D^{\prime}>0$, $D ”>0$. Alternatively, there may be situations where GM adoption confers environmental benefits (as would occur through lower pesticide use). In this case $D^{\text {' }}$ $<0, D$ ” $<0$. To assess the policy impact of variations in perceived environmental change, in the comparative static analysis we consider a simple environmental impact function of the form: $D\left(\bar{g}^{j}\right)=\delta^{j} \bar{g}^{j 2}$. For the case of environmental damage $\delta^{j}>0$ and for an environmental benefit $\delta^{j}<0$. Thus

$W^{j}=\Lambda^{j}+n^{j} \pi^{j}-D\left(\bar{g}^{j}\right)$

where $\Lambda^{j}=\int_{0}^{X_{j}^{i}} P_{j}^{i} d X_{j}^{i}+\int_{0}^{X_{i}^{i}} P_{i}^{i} d X_{i}^{i}-P_{i}^{i} X_{i}^{i}-P_{j}^{i} X_{j}^{i}$ is the consumers' surplus in country $j$ and $n^{j} \pi^{j}=n^{j}\left(\Pi^{j}-S^{j}\right)$ is aggregate producer profit net of political contributions.

The first-order-condition for the government's optimal choice of GM regulation in the political equilibrium, from equation (4a), is

$\frac{\partial \Omega^{j}}{\partial \bar{g}^{j}}=n \frac{\partial S^{j}}{\partial \bar{g}^{j}}+\alpha^{j} \frac{\partial W^{j}}{\partial \bar{g}^{j}}=0$ 
The interpretation of (4c) is that the government sets policy to balance the politically relevant marginal benefits and costs. Since the government values political contributions it must trade off the impact of a policy on political contributions against the welfare effects of the policy. The welfare effects of the policy include the perceived environmental impacts (whether positive or negative) and the changes in domestic producers' and consumers' surpluses. Observe that the manner in which lobbyists influence government policies depends critically on the properties of the political contribution schedule $\mathrm{S}^{j}$. Hence, to further characterize the equilibrium policy it is necessary to derive the optimum contribution schedule.

\section{Political Contributions in Country j (Stage 1 in country j)}

Each producer determines its political contributions so as to maximize payoffs taking account of the impact of its decisions on the government's optimal response.

Maximizing (1b) with respect to $S^{i}$ using equation (2) yields the first-order condition that

$$
\frac{\partial \Pi^{j}}{\partial S^{j}}=\frac{\partial \Pi^{j}}{\partial \bar{g}^{j}} \frac{\partial \bar{g}^{j}}{\partial S^{j}}-1=0 .
$$

Observe that, when $\frac{\partial \Pi^{j}}{\partial \bar{g}^{j}}>(<) 0$, an interior solution to (5a) only exists if $\frac{\partial \bar{g}^{j}}{\partial S^{j}}>(<) 0$.

Thus by the inverse function rule, (5a) can be rearranged to yield

$$
\frac{\partial \Pi^{j}}{\partial \bar{g}^{j}}=\frac{\partial S^{j}}{\partial \bar{g}^{j}} .
$$

Equation (5b) reveals that producers pay contributions to their government up to the point where the marginal cost of political contributions, $\frac{\partial S^{j}}{\partial \bar{g}^{j}}$, equals the marginal 
benefit in the form of higher profits, $\frac{\partial \Pi^{j}}{\partial \bar{g}^{j}}$. This is the local truthfulness condition of the common agency model described in detail by Bernheim and Whinston (1986) and Grossman and Helpman (1994). Let $S^{j *}$ be the solution to (5b).

Expanding terms in equation (5b) yields

$\left(\frac{\partial P_{j}^{j}}{\partial \bar{g}^{j}} X^{j}-\theta^{j} \frac{\partial C^{j}}{\partial \bar{g}^{j}}\right)=\frac{\partial S^{j}}{\partial \bar{g}^{j}}$.

Equation (5c) demonstrates how two opposing factors influence political contributions. The first term describes the demand effects of increasing GM content: an increase in GM usage lowers consumers' willingness to pay and thus reduces profits. The next term summarizes the usual cost effect: increased use of GM inputs lowers costs and hence raises profits. When the demand effect dominates (is dominated by) the cost effect, the left had side of (5c) is negative (positive), so that lobbying contributions decline (rise) with more permissive GM regulations. The intuition is straightforward. When the demand effect dominates, producers in country $j$ have more to gain by supporting stringent GM regulations, and therefore lobby for stricter controls; and conversely when the cost effect dominates.

Substituting (5b) in (4c) yields the equilibrium policy that is set to maximize a weighted sum of producer payoffs and welfare:

$$
\frac{\partial \Omega^{j}}{\partial \bar{g}^{j}}=\frac{\partial \Pi^{j}}{\partial \bar{g}^{j}}+\alpha^{j} \frac{\partial W^{j}}{\partial \bar{g}^{j}}=0 .
$$

Political contributions by producers in country $j$ are not independent of the GM standards set in country $i$ (the first mover). On the contrary, if the adverse demand effect in country $j$ dominates the favorable cost effect, then a permissive GM 
regulation in country $i$ induces more-intense lobbying for a stringent regulation in country $j$ (i.e. $\frac{d S^{j}}{d \bar{g}^{i}}>0$ ). This follows from the fact that $\frac{d S^{j}}{d \bar{g}^{i}}=\frac{-\left(\frac{\partial P_{j}^{j}}{\partial g^{j}} \frac{\partial X^{j}}{\partial g^{i}}\right) \frac{\partial g^{j}}{\partial S^{j}}}{\partial^{2} \Pi^{j} / \partial S^{j^{2}}}>0$ because the denominator is negative by the second-order conditions and, in the numerator, $\frac{\partial P_{j}^{j}}{\partial g^{j}}<0, \frac{\partial X^{j}}{\partial g^{i}}>0$ and, when the demand effects dominate, $\frac{\partial g^{j}}{\partial S^{j}}<0$

The intuition for this result is that when the GM content of imports from country $i$ rises and there is a sufficiently high level of aversion to GM products in country $j$, domestic producers can capture a greater share of their market by differentiating their products from those of the high GM content importers. Lobbying for tighter domestic GM regulations therefore intensifies.

The consequence of this for the government's equilibrium response to changes in the GM content of imports can be determined by totally differentiating equation (4c) using equation (5b) to yield

$\frac{d g^{j}}{d g^{i}}=-\frac{\partial^{2} \Omega^{j} / \partial g^{j} \partial g^{i}}{\partial^{2} \Omega^{j} / \partial g^{j 2}}$ where $\frac{\partial^{2} \Omega^{j}}{\partial g^{i} \partial g^{j}}=\alpha \frac{\partial P_{j}^{j}}{\partial g^{i}} \frac{\partial X_{j}^{j}}{\partial g^{j}}+\frac{\partial P_{j}^{j}}{\partial g^{j}} \frac{\partial X_{j}^{j}}{\partial g^{j}}<0$. This leads to Proposition 1: If the demand effect in country j dominates the cost effect, then the more permissive are GM regulations in country $i$ the more stringent will they be in countryj.

Equilibrium policies are thus strategic substitutes when there is a sufficiently high level of domestic aversion to GM content. The reason is that domestic producers 
lobby more intensively for stricter GM controls when they gain through product differentiation, and in a political equilibrium the policies of a self-interested government (partly) reflect the preferences of lobbyists through their political contributions, as in equation 4c. Hence the government responds by imposing more stringent regulations when faced with imports with a higher GM content. Moreover, the greater are the gains to domestic producers from stricter domestic regulations, the more stringent will be the policy response in country $j$.

An immediate corollary of this outcome is that when GM aversion in the importing country is sufficiently low so that the cost effect dominates, there will be standard policy convergence, that is, policies are strategic complements.

Two conclusions follow from this observation. First, differences in regulatory approaches across countries at least partly reflect difference in consumer preferences and comparative advantage in GM adoption, in addition perhaps to other motives. Second, lobbying in a political market accentuates the degree of policy divergence (convergence), compared with the welfare-maximizing outcome that would result without any lobbying.

\section{The Political Equilibrium in Country $i$}

Having characterized the equilibrium policy in the follower, country $j$, we now examine policy determination in country $i$, the first mover. Maximizing (1a) with respect to $X_{i}^{i}$ and $X_{j}^{i}$ yields the first-order conditions

$$
\begin{aligned}
& \frac{\partial \Pi^{i}}{\partial X_{i}^{i}}=\left(\frac{\partial P_{i}^{i}}{\partial X_{i}^{i}} X_{i}^{i}+P_{i}^{i}-\theta^{i} \frac{\partial C^{i}}{\partial X_{i}^{i}}\right)=0 \text { and } \\
& \frac{\partial \Pi^{i}}{\partial X_{j}^{i}}=\left(\frac{\partial P_{j}^{i}}{\partial X_{j}^{i}} X_{j}^{i}+P_{j}^{i}+\frac{\partial P_{j}^{i}}{\partial X_{j}^{j}} \frac{\partial X_{j}^{j}}{\partial X_{j}^{i}}-\theta^{i} \frac{\partial C^{i}}{\partial X_{j}^{i}}\right)=0 .
\end{aligned}
$$


Equation (6a) defines equilibrium sales in the domestic market, while equation (6b) defines the equilibrium level of exports. Note that by equation (6b) the producers in country $i$, the first movers, take account of the anticipated response of country $j$ producers to their decisions, that is, $\frac{\partial P_{j}^{i}}{\partial X_{j}^{j}} \frac{\partial X_{j}^{j}}{\partial X_{j}^{i}}$. Leadership thus confers a strategic advantage on country $i$ producers, yielding them a higher level of exports. That is, $\frac{\partial P_{j}^{i}}{\partial X_{j}^{j}} \frac{\partial X_{j}^{j}}{\partial X_{j}^{i}}>0$ in equation (6b)

Turning next to the government's optimum policy in country $i$, we assume again the government is self-interested and maximizes a weighted sum of political contributions received from producers and welfare so that

$$
W^{i}=\Lambda^{i}+n^{i} \pi^{i}-D\left(\bar{g}^{i}\right)
$$

where $\Lambda^{i}=\int_{0}^{X_{i}^{i}} P_{i}^{i} d X_{i}^{i}-P_{i}^{i} X_{i}^{i}$ is consumers' surplus in country $i$ and $n^{i} \pi^{i}=n^{i}\left(\Pi^{i}-S^{i}\right)$ is aggregate producer profits net of political contributions and $D\left(\bar{g}^{i}\right)=\delta^{i} \bar{g}^{i 2}$ is perceived environmental impacts. As noted earlier, when the impact is beneficial $\delta^{i}<$ 0 and when it is harmful $\delta>0$ The first-order condition for the optimal choice of GM regulation in the political equilibrium is defined by

$\frac{\partial \Omega^{i}}{\partial \bar{g}^{i}}=n \frac{\partial S^{i}}{\partial \bar{g}^{i}}+\alpha^{i} \frac{\partial W^{i}}{\partial \bar{g}^{i}}=0$

Each producer determines political contributions so as to maximize payoffs taking account of the impact of its decisions on its government's optimal response and the reaction function of the government in country $j$. Maximizing (1a) with respect to $S^{j}$ using equations (6a) and (6b) yields the first-order condition

$\frac{\partial \Pi^{i}}{\partial S^{i}}=\frac{\partial \Pi^{i}}{\partial \bar{g}^{i}} \frac{\partial \bar{g}^{i}}{\partial S^{i}}-1=0$ 
As earlier, equation (8a) can be rearranged to obtain the local truthfulness condition

$$
\frac{\partial \Pi^{i}}{\partial \bar{g}^{i}}=\frac{\partial S^{i}}{\partial \bar{g}^{i}}
$$

and can be expanded in equation ( $8 \mathrm{a})$ to yield

$$
\left(\frac{\partial P_{i}^{i}}{\partial \bar{g}^{i}} X_{i}^{i}+\frac{\partial P_{j}^{i}}{\partial \bar{g}^{i}} X_{j}^{i}+\frac{\partial P_{j}^{i}}{\partial \bar{g}^{j}} \frac{\partial \bar{g}^{j}}{\partial \bar{g}^{j}}-\theta^{i} \frac{\partial C^{i}}{\partial \bar{g}^{i}}\right) \frac{\partial \bar{g}^{i}}{\partial S^{i}}-1=0 .
$$

Equation (8c) reveals that three factors influence political contributions in the country with a first-mover advantage. The first two terms describe the demand effects of increasing GM content, which lead to lower prices and lower profits. The next term summarizes the strategic effect. Lobbyists in the first-mover country $i$ will take account of the policy reactions of the follower country in formulating their strategy. For instance, when the GM aversion effect dominates in the follower country then policies are strategic substitutes (i.e. $\frac{\partial \bar{g}^{j}}{\partial \bar{g}^{j}}<0$ ). Increased GM usage by producers in country $i$ thus leads to tighter standards in country $j$ and hence lower export sales for country $i$. Anticipating this response, producers in country $i$ will lobby less intensively than they would if policies were strategic complements. The final term in brackets defines the usual cost effect: increased use of GM inputs lowers costs and hence raises profits. When the cost effect dominates, weaker regulations improve producer profits and hence there is lobbying for more permissive GM regulations.

Substituting (8b) in (7d) yields the equilibrium policy stance in country $i$

$$
\frac{\partial \Omega^{i}}{\partial \bar{g}^{i}}=n \frac{\partial \Pi^{i}}{\partial \bar{g}^{i}}+\alpha^{i} \frac{\partial W^{i}}{\partial \bar{g}^{i}}=0
$$

By equation (9) the government policy maximizes a weighted sum of lobbyists' profits and social welfare. Compared to the social welfare-maximizing equilibrium, policies are skewed in favor of the lobbyists' preferences. 
How do policies vary with the extent of comparative advantage in GM adoption? It turns out that $\frac{d g^{i}}{d \theta^{i}}=\frac{-n(1+\alpha) \partial c^{i} / \partial g^{i}}{\partial^{2} \Omega^{i} / \partial g^{i 2}}<0$ (since by assumption $-\partial c^{i} / \partial g^{i}<0$ and by the SOCs $\left.\partial^{2} \Omega^{i} / \partial g^{i 2}<0\right)$, which leads to

Proposition 2: The greater the relative cost disadvantage of GM usage in country j, the more country $i$ will introduce less-stringent GM regulations so as to capture a greater share of the market in country j.

It follows from Propositions 1 and 2 that producers in country $i$ have to judge ex ante whether the adverse demand effects will dominate the cost effects of GM technology in country $j$ and, if not, then to lobby more for lax domestic standards the greater their cost advantage, relative to country $j$ producers, in adopting GM technology.

Finally, consider the impact of varying the environmental effects of GM adoption in country $i$. Totally differentiating (9): $\frac{d g^{i}}{d \delta^{i}}=\frac{2 \alpha^{i} \delta^{i} g^{i}}{\partial^{2} \Omega^{i} / \partial g^{i 2}}>(<) 0$ if $\delta^{i}<(>) 0$ and hence $\frac{d g^{j}}{d \delta^{i}}=\frac{d g^{j}}{d g^{i}} \frac{d g^{i}}{d \delta^{i}}<(>) 0$ if $\delta<(>) 0$. That is, differences in perceived environmental damage/benefits too result in greater divergence of standards, which leads to

Proposition 3: Environmental benefits (or lower perceived environmental damage) flowing from GM adoption in country $i$ will result in less-stringent GM regulations in country $i$. When policies are strategic substitutes, country j responds by introducing more stringent standards. 


\section{Empirical Support for Lessons from the Model}

The above political economy analysis suggests (i) that greater consumer aversion to eating GM foods, or environmental concerns with GM crop production,

may not be the only reasons why GM standards and regulations in the EU are so much more stringent than in America; and (ii) that comparative disadvantage (advantage) in the use of GM crop technology would result in support by farmers for GM standards that are strict in the EU (lax in the US).

How plausible are these conclusions? The latter result has empirical support in a new study using the GTAP computable general equilibrium model of the global economy. Anderson and Jackson (2004) find that, given GM adoption in America, farmers in the EU are better off denying themselves access to GM technology in return for a ban on imports from GM-adopting countries. Specifically, three of the scenarios they present are pertinent to the above analysis:

- Sim 1: the US, Canada and Argentina allow the adoption of GM coarse grain and oilseeds which results in a 45 percent take-up for coarse grain and 75 percent for oilseeds (with total factor productivity being higher for GM than non-GM varieties by 7.5 percent for coarse grain and 6 percent for oilseeds), and there are no adverse policy responses;

- Sim 2: Sim 1 plus the EU and hence all other countries choose to allow adoption of these GM crop varieties, which leads to adoption rates equal to two-thirds those of the first adopters in Latin America and Australia and equal to one-third in the EU and elsewhere (given their less-favorable land use environment for cost-effective adoption); and 
- Sim 3: Sim 1 plus the EU imposes a moratorium that effectively bans imports of those two sets of crops (both GM and non-GM varieties) from the three GM-adopting countries, and discourages other countries from following the American decision to allow GM crop production.

A sample of the results from those scenarios are summarized in Table 2. If there is no adverse policy response abroad (Sim 1), GM adoption in those three countries raises US economic welfare by $\$ 939$ million per year. But since these three countries account for three-fifths of the world's soybeans exports and four-fifths of global maize exports, their GM adoption also raises welfare in the EU and the rest of the world through an improvement in the latter's terms of trade, so the global gain from limited adoption of that new technology is $\$ 2.3$ billion per year. US farmers are not among the beneficiaries, however, because their widespread GM adoption depresses their terms of trade: their real household incomes (taking account also of their offfarm earnings) are depressed by an average of 0.18 percent. Nor are EU farmers among the beneficiaries in the EU: even though they do not grow the less-preferred GM varieties, the fall in the price of the GM substitute causes the price even of the GM-free varieties of these crops to fall slightly, and their real household incomes drop by 0.03 percent.

Were the EU to drop its moratorium and allow production and importation of GM varieties of these crops, and were all other countries to do likewise, Sim 2 shows that US welfare would drop because of the greater competition, but only slightly, and the fall in real incomes of US farm households would be 0.3 instead of 0.2 percent. EU aggregate welfare would be greater both because of the lower cost of farm 
production and the improvement in its international terms of trade, but EU farm household income would fall more than in Sim 1.

By contrast, imposing the moratorium as in Sim 3 (which assumes also that other countries also refrain from adopting) raises EU farm household incomes so that they are 0.8 percent higher than in the other scenarios. In that simulation, overall welfare in the EU-15 would rise if its citizens valued the knowledge that they are not consuming or producing GM food at more than $(3145+267=) \$ 3412$ million, which is just $\$ 9$ per capita per year. These results are thus not inconsistent with the theoretical proposition developed earlier in the paper that there can be a convergence of policy interests between consumer, environmental and farmer groups in the EU even when that policy denies the farmers access to a new technology. ${ }^{5}$

\section{Conclusions}

Both the theory and the simulation results presented above take us some way toward understanding why equally affluent societies on opposite sides of the Atlantic have adopted polar opposite policy positions on GM food technology. More generally, our political economy theory is innovative in showing that when firms lobby policy makers to influence standards and consumers care about the choice of standard, it is possible that increased competition can lead to strategic incentives to raise standards (not just to engage in a 'race to the bottom', which has been the thrust of much of the earlier literature in this area).

There are a number of omitted issues that could be added to the analysis. Perhaps of greatest significance is the absence of explicit environmental and consumer lobby groups. Arguably, this simplification is not unreasonable in the 
context of this model. While environmental lobby groups remain active and have maintained a high profile on the issue of GM technology, they typically seek to influence policies through publicity campaigns designed to alter public opinion, rather than by paying political contributions. The influence of environmental campaigns, while not explicitly modeled, is thus captured implicitly by the aversion parameter $\gamma^{6}$ In future research it could be useful to explore the interactions between producer and environmental groups together with bilateral and multi-regional trade. The complexity of the problem is such that analytical solutions may not be derivable, in which case a numerical CGE simulation approach may be necessary.

This paper has also ignored the important role played by agricultural biotechnology firms, which have a clear incentive to promote GM adoption. If they are more prevalent, more politically influential, and/or more advanced in the US than in the EU, that would be an additional reason for the observed difference in GM policies. $^{7}$

Finally, note that while our analysis and discussion has focused on the case of consumer aversion to GM products, the results are reversed if instead consumers have a preference for GM crops (as potentially could be the case with nutritionallyenhanced 'golden' rice), or if the GM variety is for a crop that has major environmental savings, for example in terms of requiring less farm chemicals (as with GM cotton) - especially if that crop is not supplying a food staple. The fact that GM cotton is increasingly being adopted in a number of developing countries is thus understandable. The fact that 'golden' rice has yet to be adopted by those same developing countries - even though the patent holder is apparently offering free use of the technology - may have to do with the fear that their exports of not just rice but 
also other foods would face greater barriers to EU and other markets once their GMfree status is tarnished. 


\section{References}

Anderson, K. and L.A. Jackson (2004), 'Standards, Trade and Protection: The Case of

GMOs', paper for the Annual Meetings of the American Agricultural Economics Association, Denver CO, 1-3 August.

Baron, D. P. (2004), “ Electoral Competition with Informed and Uninformed Voters,” American Political Science Review 88, 33-47.

Barrett, S. (1994), “Strategic Environmental Policy and International Trade,” Journal of Public Economics 54: 325-38.

Bernauer, T. (2003), Genes, Trade and Regulation: The Seeds of Conflict in Food Biotechnology, Princeton: Princeton University Press.

Bernheim, B. and M. Whinston (1986), "Menu Auctions, Resource Allocation, and Economic Influence," Quarterly Journal of Economics 101: 1-31.

Bockstael, N. (1984), “The Welfare Implications of Minimum Quality Standards,” American Journal of Agricultural Economics 66: 466-71.

Boom, A. (1985), “Asymmetric International Minimum Quality Standards and Vertical Differentiation," Journal of Industrial Economics 18: 101-20. 
Bredahl, M., A. Schmitz, and J. Hillman (1987), "Rent Seeking in International Trade: The Great Tomato War," Journal of Agricultural Economics 69(1): 1-10, February.

Copeland, B. and S. Taylor (1995), “Trade and Environment: A Partial Synthesis,” American Journal of Agricultural Economics 77: 765-71.

Dixit, A. and J. Stiglitz (1977), "Monopolistic Competition and Optimum Product Diversity," American Economic Review 67(3): 297-308.

Feder, G., R. Just and D. Zilberman (1985), “Adoption of Agricultural Innovations in Developing Countries: A Survey," Economic Development and Cultural Change 33: 255-98.

Fernandez-Cornejo, J and W. McBride (2000), “Genetically Engineered Crops for Pest Management in US Agriculture: Farm Level Effects.” Agricultural Economic Report No. 786, Washington, DC: Economic Research Service, US Department of Agriculture, April.

Fernandez-Cornejo, J. and W. McBride (2002), “Adoption of Bio-engineered Crops.” Agricultural Economic Report No. 810, Washington, DC: Economic Research Service, US Department of Agriculture.

Fischer, R. and P. Serra (2000), “Standards and Protection,” Journal of International Economics 52: 377-400. 
Flam, H. and E. Helpman (1987), "Vertical Product Differentiation and North-South Trade," American Economic Review 77(5): 810-22.

Fulton, M. and K. Giannakis (2004), 'Inserting GM Products into the Food Chain: The Market and Welfare Effects of Different Labeling and Regulatory Regimes', American Journal of Agricultural Economics 86(1): 42-60, February.

Grossman, G. and E. Helpman (1994), "Protection for Sale," American Economic Review 84(4): 833-50.

Grossman, G.M. and E. Helpman (1995), 'Trade Wars and Trade Talks’, Journal of Political Economy 103(4): 675-708, August.

Lapan, H.E. and G.C. Moschini (2004), 'Innovation and Trade with Endogenous Market Failure: The Case of Genetically Modified Products', American Journal of Agricultural Economics 86(3): 634-48, August.

Marra, M., P. Pardey and J. Alston (2002), “The Payoffs to Agricultural Biotechnology: An Assessment of the Evidence,” EPTD Discussion Paper No. 87, Washington DC: International Food Policy Research Institute.

Riordan, M. (1986), “Monopolistic Competition With Experience Goods,” Quarterly Journal of Economics 101(2): 265-80. 
Van Meijl, H. and F. van Tongeren (2002), “Diffusion of Gains from Biotechnology and the European Union's Common Agricultural Policy," Paper presented at the Fifth Annual Conference on Global Trade Analysis, Taipei, Taiwan, 5-7 June. 
Table 1: Sources of the European Union's non-EU imports of maize, soybeans and canola, by volume, 1995 to 2001

(percent)

\begin{tabular}{|c|c|c|c|}
\hline & 1995-97 & 1999-2001 & $\begin{array}{r}\text { Supplier's } \\
\text { share of } \\
\text { world (excl. } \\
\text { intra-EU) } \\
\text { exports, } \\
\text { 1999-2001 }\end{array}$ \\
\hline \multicolumn{4}{|l|}{ Maize } \\
\hline United States & 64 & 2 & 65 \\
\hline Argentina & 18 & 72 & 13 \\
\hline Brazil & 0 & 11 & 3 \\
\hline Rest of world & 1 & 6 & 17 \\
\hline TOTAL & 100 & 100 & 100 \\
\hline \multicolumn{4}{|l|}{ Soybeans } \\
\hline United States & 60 & 42 & 54 \\
\hline Argentina & 9 & 4 & 9 \\
\hline Brazil & 24 & 47 & 27 \\
\hline Rest of world & 4 & 5 & 10 \\
\hline TOTAL & 100 & 100 & 100 \\
\hline \multicolumn{4}{|c|}{ Canola (rapeseed) } \\
\hline Canada & 54 & 0 & 59 \\
\hline Australia & 0 & 22 & 24 \\
\hline Central Europe & 39 & 70 & 12 \\
\hline Rest of world & 7 & 8 & 5 \\
\hline TOTAL & 100 & 100 & 100 \\
\hline
\end{tabular}

Source: Drawn from www.affa.gov.au/gmmarkets, based on EU official trade data 
Table 2: National economic welfare and real farm household income effects of GM coarse grain and oilseed adoption by the US, Canada and Argentina

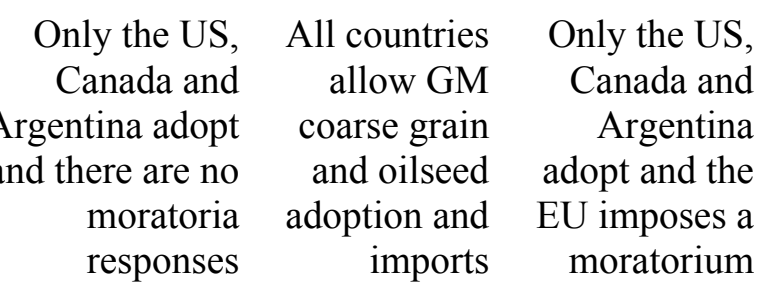

$\operatorname{Sim} 1 \quad \operatorname{Sim} 3 \quad \operatorname{Sim} 2$

Change in real farm

household income (\%):

$\begin{array}{llrr}\text { United States } & -0.18 & -0.29 & -0.36 \\ \text { EU-15 } & -0.03 & -0.08 & 0.74\end{array}$

\section{Change in national}

economic welfare

(equivalent variation in

income, US\$ million):

United States

939

628

EU-15

WORLD

${ }^{a}$ Not counting any benefit EU consumers derive from knowing that they are not consuming imported GM food.

Source: Anderson and Jackson (2004). 


\section{Endnotes}

${ }^{1}$ That prospect for boosting economic growth through investment in agricultural biotech research was recently rated the second-highest, in terms of benefit-cost ratio, of all the prime opportunities to help achieve the United Nations' Millennium Development Goals, according to a panel of distinguished economists including several Nobel Laureates. See www.copenhagenconsensus.com

${ }^{2}$ Typically the literature that focuses on firms' quality differentiation decisions uses monopolistic competition models to capture firms' production (Dixit and Stiglitz 1977; Riordan 1986). Since our model describes an agricultural industry composed of many small, price-taking firms, the firms' strategic activities include lobbying and producing crops. In our model, standards refer to allowable GM content (including zero tolerance) and these standards have implications for both producer costs and consumer demand.

${ }^{3}$ For notational clarity we suppress other terms in the cost function which are held constant throughout the analysis. Thus, $\mathrm{z}$ and $\mathrm{r}$ are implicitly subsumed in $\mathrm{C}^{\mathrm{i}}$. Note also that from the production function $\partial C^{i} / \partial X^{i}>0, \partial C^{i} / \partial \tilde{g}^{i}<0, \partial C^{i} / \partial X^{i} \partial \tilde{g}^{i}<0$.

${ }^{4}$ In fact farm size may be a surrogate for other important factors influencing farmer adoption, including wealth, risk preferences and access to credit (Feder, Just and Zilberman 1985).

${ }^{5}$ These simulations assume the cost-saving to GM farmers is net of the premium paid to biotech firms for GM seed, the proceeds of which are ignored in that empirical model (which is consistent with the political economy model presented earlier). 
${ }^{6}$ One possible reason why environmental groups seldom lobby through the payment of political contribution is that they typically deal with "particularist" policies where the benefits of lobbying for the easing of environmental restrictions are concentrated while the (perceived or actual) environmental costs are more widely dispersed across the community (Baron 2004). Hence free-riding and public goods problems may make it more difficult for environmental groups to raise sufficient funds to directly lobby the government through political contributions.

${ }^{7}$ Both Fulton and Giannakas (2004) and Lapan and Moschini (2004) include biotech R\&D producers in their economic models. Adding them to our political economy model would be somewhat more complex, however. 